\title{
The Dwindling Language of Type Specimens 1901-1914
}

At the turn of the twentieth-century, type specimen books were the primary vehicles for advertising commercial typography. Their function was to display letterforms, but for the design historian they can also reveal the wider values of the printing trade. Late nineteenth-century specimens presented their decorative typefaces through diverse text fragments that point to typography's wider social involvements, but in the 1900 s this convention began to change. This essay explores the changing role of texts in specimen design through a corpus of Australian samples produced in 1901-1914. I argue that the new uses of language reflect a wider shift in the anonymous typographers' trade identity, showcasing a practice concerned less with its old myths of knowledge and skill, and more interested in the present acts of its own labour. The essay gives evidence of how specimen design reflected trade identity in the regional Australian market, but unravelling the design structures of these books also has implications for their wider study. Understanding how specimens were designed expands their potential use as sources in studying the anonymous designers who created them.

keywords type specimen books, typography, australian design

\section{Introduction}

The specimen books of the Victorian printing trade were filled with a chaotic diversity of ornamental typefaces, composed as an equally rambling series of text fragments. Each specimen book was the authored product of multiple anonymous hands, and as advertisements they were as much a means for representing the typographic worker as a showcase for letterforms. To read the texts that typographers selected for display is to gain an impression of the workers who pieced them together, whose anonymity otherwise obstructs individual characterisation. And if not an accurate portrayal of the trade, it is at least an indication of how they chose to promote themselves and their work. Typographers used their wide-ranging texts to evaluate type designs and demonstrate the spectrum of subjects passing through their hands, highlighting their role in commodifying and distributing information (O'Neill 2012: 134, 251). These texts projected an image of trade typographers as having aesthetic concerns and embracing a broad interest in their world.

The examples discussed in this essay, however, are far less dramatic than those of the nineteenth-century. Here, I look at a corpus of Australian specimens that were published in 1901-1914, drawing out the new linguistic techniques appearing at this time. Despite their dull outward character, these examples are no less an encapsulation of the typographers who composed them. Indeed, following in the wake of nineteenth-century industrial 
theme 3

identity

Figure 1.

Australian Type

Foundry (1908)

Type, Borders, Etc., 56-56 strand 3

authorship and anonymous design

reforms, they show a significant shift in the identity of the trade, which began to distance itself from knowledge and aesthetics and embrace physical labour.

\section{Australian specimens, 1901-1914}

Given their ephemeral status, only seven Australian type specimens have survived in public collection from the period 1901-1914. Most of the remaining books are products of Wimble's Australian Type Foundry (ATF), a major regional supplier established in 1900 by the protectionist Fred Wimble (ATF 1901, 1904, 1908; F. T. Wimble \& Co. C.1913). The other catalogues in this corpus promote the work of a printing supplier (Gordon \& Gotch C.1908), a commercial printer (Edward Lee \& Co. 1913), and a government department (New South Wales Government Printer 1909). Although the sample is limited, these specimens still show several common departures from the linguistic conventions of nineteenth-century specimens, suggesting that they represent new standard approaches to the marketing of typography at that time.

The broad range of texts in nineteenth-century specimens showed the extended reach of printing as typographers looked out onto the wider social applications of their work. From this perspective, the 1901 ATF specimen made the first dramatic departure for twentiethcentury specimen design. This first catalogue from a newly formed company directly contrasts the esoteric subject matter of earlier books by presenting only the language of direct self-promotion. More than $70 \%$ of its samples name objects for printing - types, furniture, lye solutions and machine parts - all of which were available for purchase. The technique continues in the company's 1904 and 1908 catalogues, which describe nothing of the outside world, only detailing the ATF's services, the typographers' tools, and the physical space in which they worked (Fig. 1). Even the typefaces themselves are distanced from their aesthetic qualities and reduced to the status of physical resources, which are no longer to be appraised for their style or beauty. This is clearest in one sample, where the ATF typographer writes: "This is a specimen of hard metal type" (ATF 1901: 5). In this line there is no typographic evaluation, just a reminder that printed letters were really only physical things. Foregoing the commentaries of typographic form and reflections on literature and history that were standard in earlier specimens, the ATF typographer uses his texts only to draw attention to his manual task.

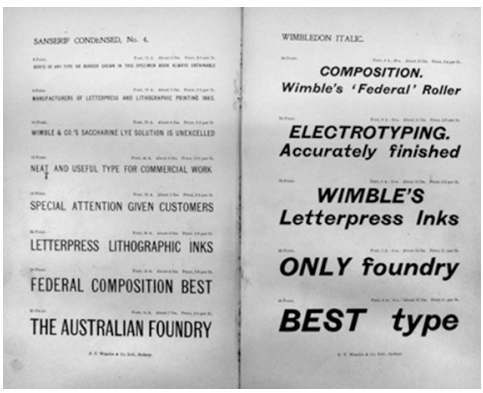

The second departure from nineteenth-century specimen language further underlines the twentieth-century typographer's newfound emphasis on materiality. This second technique appears across several pages of the 1909 Government Printer's catalogue, where the texts showcasing the typefaces De Vinne and Edina are restricted to simply naming the designs (Fig. 2). Other pages in the book still resemble earlier specimens by drawing different texts from government publications; this places this newer approach 
in stark contrast as a particularly unimaginative solution. Previously a typeface may have been named in its sample, as in "The Stylus is one of the Modern" (Batson 1886: 5), but such a statement involves both typographic categorisation and a philosophy of beauty in printing, and is primarily an appraisal of the designed forms of letters. In contrast, the Government Printer's texts are the mere identification of material objects, much like the ATF's "hard metal types". By only naming his typeface, the typographer refused to engage in aesthetic discussion, and by failing to show the kinds of texts to which the typefaces could be applied, he neglected the possibility of their commercial application or attachment to cultural meanings. Thus it appears the twentieth-century typographer was abandoning information, or the text content of his craft, in favour of its mechanical form.

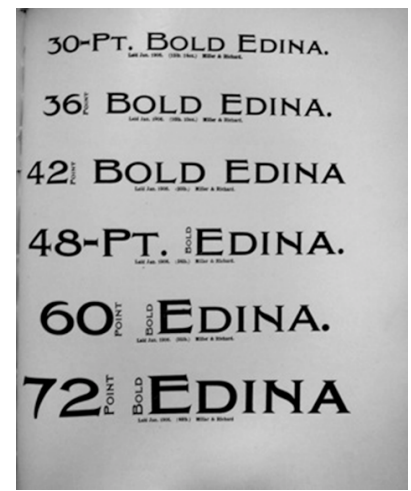

Figure 2. NSW Government Printer (1909), Types Received, 16.

The Government Printer's strategy soon found much wider application in the c.1913 Edward Lee catalogue. In that book, the designer rarely represents the wider use-value of his types, composing more than half of his samples through the name or material size of the typeface. The result is that the subjective interpretation of types was removed from specimen language, leaving only objective identification.

Through these new techniques - the naming of types and use of direct promotional texts - we see the typographers of the 1900 disengaging themselves from language. While promoting their own skills and work, they no longer seem to revel in their capacity to write or edit text, or engage with design and communicative value. They focus only on the material resources at hand in the printing workshop and the tools of their own labour. From the global interests revealed through earlier specimen texts, the typographers' outlook was refocused on their immediate working environment. In a final demonstration of the growing refusal to recognise language as part of their work, the Edward Lee typographer even adopted Wimble's promotional text directly from the typefounder's own specimen (Edward Lee 1913: 31). Thus, in this instance, both types and texts arrived as fixed resources for mobilisation rather than reflection.

Closing the period, Wimble's 1913 catalogue introduced a third new approach. The book revisits older traditions of specimen language, but its application is only a stunted mannerism. The typographer finally makes reference again outside the workshop, but this is not a return to the rambling of the 1890 s. Across the page, the same word is repeated in every line (Fig. 3). In fact, only a few different words appear across the whole book, "Christians" (Wimble 1913: 4-8) being by far the most common. Gone is the delicate consideration of language in relation to typeface, which stipulated that every face 
theme 3

identity

Figure 3 .

F. T. Wimble \& Co (1913) Catalogue, 4. strand 3

authorship and anonymous design

should have its own text suited to the design. What remains is the rote repetition of a standardised idea.

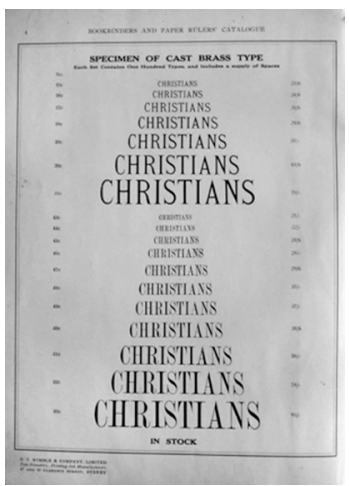

Through these three departures from the specimen practices of the nineteenth century, we see a diminishing capacity to handle texts. The broad collections of events, objects and people that illustrate the typographers' place in their wider world are missing, replaced by an impression focused squarely on the mechanical environment of the printing workshop. As commercial artefacts, the books continue to operate in the same manner they had previously; typographers still had individual selection of their texts, and the texts were an integral part of how they promoted their work and their professional skills, but how they chose to construct these texts had changed. The new linguistic techniques do not suggest the typographer as a knowledgeable and able writer, or as having a broad interest in humanistic knowledge, but as merely having the capacity for reproduction. The texts present a limiting of the typographer's field of vision, suggesting new values taking hold within the trade. The question is why should such a shift appear at the beginning of the twentieth century?

\section{Union typographers}

The linguistic scope of nineteenth-century specimens bore the influence of the 'Art Preservative'. This internal myth of the printing trades defined the noble identity of typography (Walsh 1893: 68-69); it was a belief in the scholarly mission of printing, valorising the typographer's breadth of knowledge and their capacity over not only typographic form but also text content. It bestowed on typographers the task of preserving the knowledge of other disciplines, providing them a heightened view of their own education and intellect. As such, typographers emphasised their capacity to work with text. Older Australian specimens explicitly named the Art Preservative (Batson 1886: 122), and it can also be interpreted in the typographers' inclusion of such a wide scope of topics in publications that were self-promoting advertisements. The Art Preservative was an impression of typographers' middle-class status as educated artisans, an impression that regularly stood at odds with the dire working conditions they faced.

Through the late nineteenth-century, Australian typographers encountered an increasingly tenuous position through economic downturn and changing employment conditions. Like the trades in America, Britain and Europe, they began forming unions from the 1850s, but were slow to abandon their older middle-class identity by joining with other working-class 
movements (Hagan 1966: 288-289). By the depression of the 1890 their involvement in working-class demonstrations accelerated, and for labour historian James Hagan (1966: 293), they began shedding traditions in an effort to maintain higher wages. The transition from Art Preservative to trade union was reflected in changing attitudes to apprentices. Trade journals of the 1880 s criticised apprentices for having insufficient education for the intellectual craft of typography (Eckersall 1980: 41-42): emphasis was given to the trade's intelligence over its manual exertion. By the 1900 s the position reversed and they were criticised for lacking physical strength (Eckersall 1980: 95). Arguably, the Art Preservative ended when typographic education was extracted from the traditional apprenticeship system and placed within the new Working Men's Colleges in 1899. The schools distanced the new intake from the internal mythologies of older generations by giving them a state education in manual skills, thus wearing down the pretence that their role was as preservers of knowledge.

Early twentieth-century specimens are a conclusion to the printing trade's slow transition in adopting unionist ideas. They reflect a re-focusing of attentions, away from the scope of knowledge contained in print and toward the physical task of typesetting. In their efforts to establish base standards of employment, the unions defined the typographer's conditions through quantified labour: pay relating directly to the amount of type-metal set per hour. The new strategies to specimen language - identifying types, observing printing tools, and the rote repetition of de-contextualised words - show the broader move from a conception of the trade as founded on dexterous knowledge toward one that emphasised the immediate work of the hands. This new specimen language rescued the union compositor from the pressures of knowledge and aesthetics. Revealing the final settling of the labour transformations brought on by unionism, these new text structures mark a self-perceived transition in identity from the scholar to the labourer.

\section{Conclusion}

The new twentieth-century approaches to specimen texts mark the decline of one of the major design practices of the Victorian-era printing trade. While before, text fragments produced an aesthetic commentary veiled in the guise of worldly knowledge, typographers of the early twentieth century became increasingly attentive to the material typographic subject itself. When considering how to present types, these workers appear to not reflect on the potentialities of application, but on the basic resource, meaning that instead of the grand external vision of empire-building trade networks, history and the arts, the specimens became introverted. The shift followed changes to the trade's education and political status, marking the demise of the typographer as they were reduced to the status of what had been derided in the 1870 as "type shovellers" (Eckersall 1980: 41). The typographer became the compositor, focused only on manual technique and labour processes. It is the declining mythology of the scholar and the confirmation of working-class values, a shift in identity from design to production.

\section{References}

Batson \& Co. (1886) First specimen book, Sydney: Batson \& Co. Eckersall, K. (1980) Young Caxton: A history of aims in printing education in Melbourne 1870-1970, Melbourne: Melbourne College of Printing and Graphic Arts.

Edward Lee \& Co. (c.1913) Our type faces, Sydney: Edward Lee \& Co.

F. T. Wimble \& Co. (1913) Catalogue of bookbinders and paper rulers' machinery and sundries, Sydney: F. T. Wimble \& Co. 
Gordon \& Gotch (c.1908) Specimens of type, presses and printing material, Sydney: Gordon \& Gotch.

Hagan, J. (1966) Printers and politics: A history of Australian printing unions 1850-1950, Canberra: Australian National University Press.

New South Wales Government Printer (1909) Specimens of types received at the Government Printing Office, Sydney: William Gullick.

O'Neill, J. (2012) The design and social meaning of Australian type specimen books, 1880-1901, PhD diss.: University of New South Wales.

Walsh, W. S. (1893) Handy book of literary curiosities, Philadelphia: J. P. Lippincott. Websdale Shoosmith \& Company (1898) Specimens of printing types, Sydney: Websdale Shoosmith \& Co.

Wimble's Australian Type Foundry (1901) Specimens of type and borders, Sydney: F. T. Wimble \& Co.

Wimble's Australian Type Foundry (1904) Specimens of type and borders, Sydney: F. T. Wimble \& Co.

Wimble's Australian Type Foundry (1908) Type, borders, etc., Sydney: F. T. Wimble \& Co. 